\title{
Efectividad de la aplicación de caldos minerales y biofertilizantes para el control de la enfermedad del Damping off (mal del talluelo, tizón foliar y bacteriosis) en Pinus caribaea'
}

\author{
Facultad de Recursos Naturales y Medio Ambiente (FARENA) \\ Bluefields Indian \& Caribbean University (BICU)
}

\section{RESUMEN}

El complejo de enfermedades hongos y bacterias conocido como Damping off causante de la enfermedad denominada mal del talluelo, Tizón Foliar y/o Bacteriosis, es actualmente el principal problema fitosanitario del género Pinus en el sector forestal nicaragüense. Su presencia en viveros y en masas forestales impide el aprovechamiento de especies tan productivas como Pinus caribaea. Se ignora el efecto de la utilización de tratamientos preventivos y/o curativos a base de biofertilizantes líquidos y caldos minerales. En esta investigación experimental se utilizan cinco tratamientos y el registro de variables fitosanitarias y fenológicas a fin de conocer la acción de control y la afectación al desarrollo de la planta. Se aplico la prueba de Análisis de varianza (ANOVA) para analizar los datos con un $95 \%$ de confiabilidad estadística. La aplicación Caldo Sulfacalcio (T1) y Biofertilizante (T2), y las combinaciones de estos (T3) caldos se pudieron prevenir la propagación de los patógenos causantes del mal del talluelo o Damping off, Tizón Foliar y Bacteriosis post germinación a las demás plantas teniendo como resultado (P-valor $>0.05$ ). Los caldos minerales y biofertilizantes y sus mezclas ensayadas en esta investigación, reducen la incidencia del mal del talluelo (Damping off) en Pino Caribe (Pinus caribaea), en condiciones post-emergerte de plántulas. Presentando una mayor efectividad la apli-

Presentado en 29-08-2017; aprobado en 30-09-2017 cación de la mezcla de calcio sulfacalcio y biofertilizantes (T3). A fin de poder corroborar estos datos se debe repetir esta investigación y mejorar incluyendo otras especies forestales tantos de coníferas como de hojas anchas.

Palabras claves: Patogenicidad, resistencia, Pinus, supervivencia, nutrición.

\section{INTRODUCCIÓN}

De acuerdo con los resultados del Inventario Nacional Forestal (INAFOR, 2008), los bosques de conífera maduros ocupan un área de 374,739 ha, seguido de las coníferas en desarrollo con 20,586 ha. $\mathrm{Su}$ distribución predomina en la Región Autónoma Costa Caribe Norte (RACCN) y en el Departamento de Nueva Segovia. Estos bosques son considerados uno de los recursos más valiosos por su importancia económica y la diversidad de su uso, tanto para madera preciosa como para la obtención de subproductos de la misma. Representan además un gran potencial turístico generador de divisas y un atractivo para importantes inversiones al país. También contribuyen a la generación de oxígeno y al equilibrio climático de nuestro planeta. Así mismo proporcionan y preservan un hábitat natural indispensable para la vida silvestre (Altieri, 1997).

Entre 1999 y 2001, los bosques de pino de la región central-norte de Nicaragua habían sufrido un severo ataque causado por insectos de la corteza, principal- 


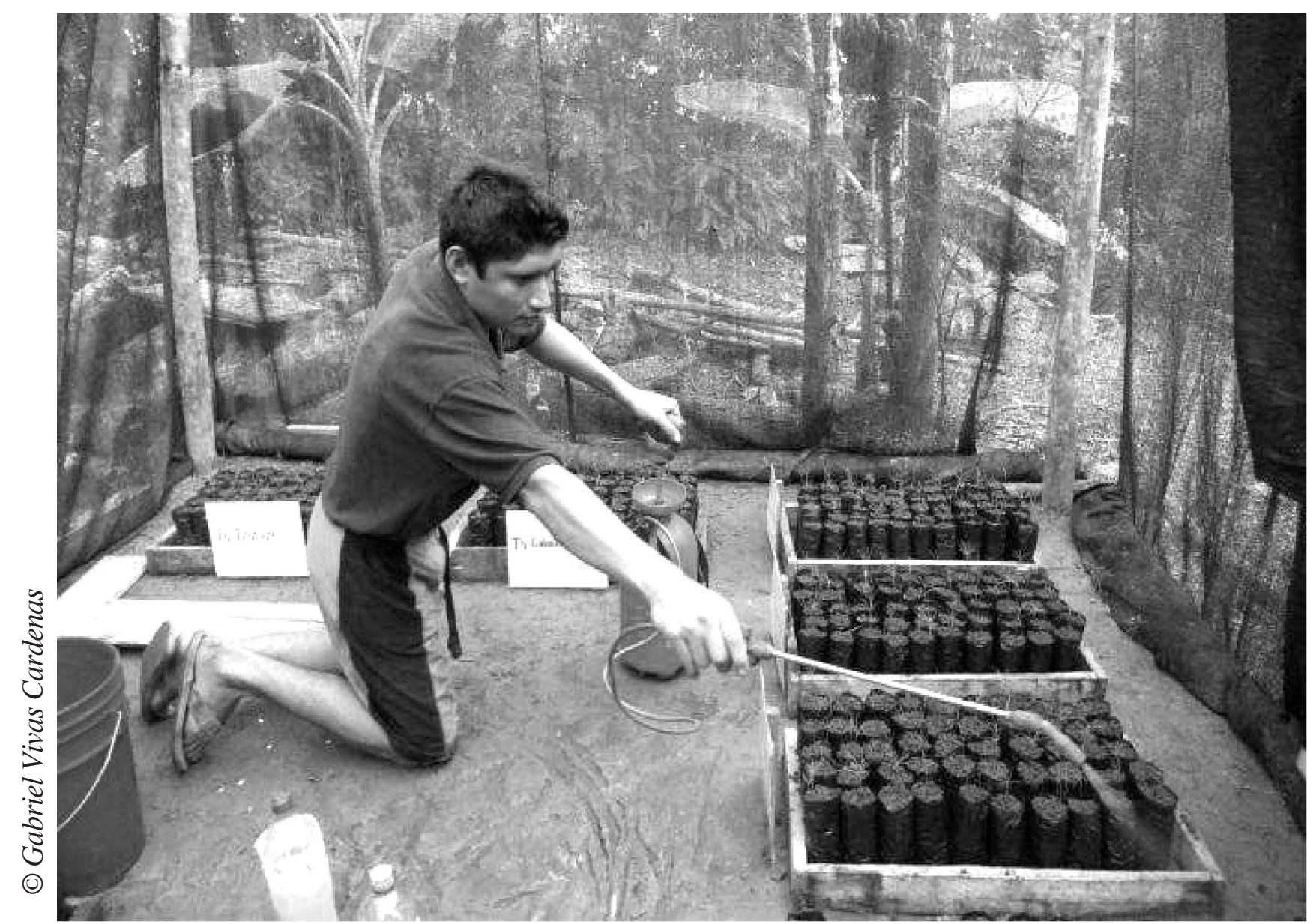

Aplicando el tratamiento preventivo de la investigación en los almácigos. Foto: Gabriel Vivas Cárdenas

mente por el descortezador (Dendroctonus frontalis Zimm) y otros insectos descortezadores asociados. El daño directo producido por estos ataques y las medidas de control físico aplicadas al bosque fueron las causas principales de la eliminación del 50\%, aproximadamente, del área forestal del departamento de Nueva Segovia, ocasionando pérdidas cuantiosas (INAFOR, 2006).

Para el año 2005, los árboles de regeneración natural presentaron serios daños en el follaje y algunas muertes. Los daños producidos fueron atribuidos a los insectos descortezadores, sin embargo, también estaban relacionados con la presencia de enfermedades. En la actualidad se han incrementado los perjuicios causados por agentes productores de enfermedades en los árboles de pino de la zona. Los síntomas se presentan en las acículas, algunos son manchas o tizones, amarillamiento generalizado del follaje, enrojecimiento y muerte de los árboles, principalmente en los de regeneración natural (Alcaldía San Fernando, 2007).

Patton (2003) refiere que los hongos que atacan al follaje de los pinos como: Dothistro mapini Hulbary y Lecanosticta acicala Thuem y complejo de hongos asociados, ocasionan crecimiento anormal de los árboles, reducción en el crecimiento e inclusive ocasionadno su muerte, siendo las más susceptibles plantaciones jóvenes. El mayor problema en vivero es con la enfermedad fungosa llamada Damping off, que produce la podredumbre del cuello de la plántula en las primeras etapas en vivero (Gordón, 2015).

Se previene esta enfermedad utilizando sustratos ricos en arena, grava y utilizando semillas provenientes de padres resistentes a esta enfermedad. También se debe tener el cuidado de hacer la propagación de plántulas por siembra directa en las bolsas de polietileno y de situar los bancales de tal forma que reciban 
la mayor cantidad de radiación solar, lo cual permita también una buena de aireación para evitar la humedad excesiva. La razón de todas estas prácticas es la de no crear condiciones para la proliferación del hongo causante del Damping off (Moya A. 1975).

Considerando la nueva problemática presentada en los bosques de pino (aparición de tizones, marchitamientos e incluso muerte de árboles adultos, sobre todo en regeneración natural) ha surgido la necesidad de su estudio para encontrar soluciones prácticas y sostenibles a estos problemas que tienen un impacto negativo en el ámbito socioeconómico y ecológico de las masas forestales (Birchler, et al 1998).

Este estudio enfocó sus aportes hacia la generación de información acerca de las enfermedades que afectan los pinares en Nicaragua, ya que no se ha realizado ninguna investigación que contribuya a su conocimiento ni al comportamiento que presentan ni a la efectividad que puede tener el uso de caldos minerales para el control del damping off (mal del talluelo, tizón foliar y bacteriosis) en viveros forestales con plántulas de Pino Caribe (Pinus caribaea). Con la información generada de esta investigación se identifican métodos de control preventivo de este complejo de hongos, que a su vez, pueden tener resultados efectivos con otros patógenos. Además de su efectividad se debe resaltar su eco sostenibilidad con el medio ambiente.

\section{MATERIALES Y MÉTODOS}

El ensayo se llevó a cabo en el municipio de Bluefields, cabecera regional de la Región Autónoma Costa Caribe Sur (RACCS). El experimento se estableció en el vivero del Ministerio del Ambiente y los Recursos Naturales (MARENA). La zona de estudio se caracteriza por presentar un clima tropical húmedo de selva con temperaturas que oscilan entre $24^{\circ} \mathrm{C}$ y 30 ${ }^{\circ} \mathrm{C}$. Basado en la clasificación de zonas de vida de Holdridge se le considera una zona húmeda, con precipitaciones anuales de 2,000 a 4,000 mm distribuidas de nueve a diez meses, siendo el mes más lluvioso el de mayo. La región es baja y pantanosa a lo largo de la costa, no excediendo los $30 \mathrm{msnm}$. Se ubica entre las coordenadas $12^{\circ} 14^{\prime}$ latitud norte y $83^{\circ} 45^{\prime}$ de longitud oeste (PNUD, 2006).
Este estudio con diseño experimental aleatorio simple se hizo mediante enfoque cuantitativo, debido a la manipulación de variables específicas y con el fin de obtener datos alométricos para el análisis del comportamiento de enfermedades como Damping off o mal del talluelo, (tizón foliar y bacteriosis), en plántulas de Pino Caribe (Pinus caribaea). Estas plántulas fueron sometidas a tratamientos de control a base de dos caldos minerales con diferentes dosis y biofertilizantes con sus combinaciones.

Las semillas se compraron en el Centro de Mejoramiento Genético Forestal y el Banco de Semillas (MGF\&BS) del Instituto Nacional Forestal (INAFOR). Esto a fin de garantizar la mayor confiabilidad y calidad de la semilla para el experimento. Según la medición de las variables, esta investigación es de corte transversal. El desarrollo de la investigación estuvo previsto para ciento veinte días (cuatro meses) de campo (ciclo productivo) y noventa días (tres meses) para el análisis de datos y presentación de resultados, lo que representa un ciclo aproximado de siete meses.

El muestreo aleatorio simple (M.A.S.) se realizó con frecuencia de dos por semana. Se muestrearon 50 plantas por cada tratamiento (100\%)para reducir al máximo el error experimental, dejando únicamente la variabilidad normal de las plantas las cuales se controlan con un 5\% (0.05) de error admisible, lo que responde a un diseño completamente aleatorio (DCA), asegurando de esta forma la igualdad de las condiciones en el experimento y evitando un sesgo estadístico, con un margen de confianza de un $95 \%$ y con un margen de error de 5\%.Se muestreó la totalidad de las plantas,

Los datos obtenidos fueron procesados en el programa estadístico R (R-Development-Core-Team, 2013) y SPSS (IBM $®$ Statistical SPSS, 2016). Todas las variables cuantitativas fueron evaluadas para comprobar la normalidad y homogeneidad de varianzas. Bajo este supuesto fueron aplicadas pruebas de análisis de varianza (ANOVA) y diferencia mínima significativa (DMS) de Fisher con $\alpha=0.05$. Esto con el fin de identificar las diferencias en las variables evaluadas para cada tratamiento experimental. 
Tabla 1. Tratamientos experimentales.

\begin{tabular}{|c|l|c|}
\hline $\begin{array}{c}\text { Código } \\
\mathrm{T}_{1}\end{array}$ & \multicolumn{1}{|c}{ Tratamientos } & Réplicas \\
\hline $\mathrm{T}_{2}$ & Biofertilizante a razón de 1 cc/litro de agua. & 50 \\
\hline $\mathrm{T}_{3}$ & $\begin{array}{l}\text { Caldo sulfacalcio }(1 \mathrm{cc} / \text { litro de agua })+\text { biofertilizante }(10 \mathrm{cc} / \text { litro de } \\
\text { agua). }\end{array}$ & 50 \\
\hline $\mathrm{T}_{4}$ & Fungicida-bactericida Phyton 24 (3 cc/Litro de agua). & 50 \\
\hline $\mathrm{T}_{5}$ & Testigo (nula aplicación de tratamientos). & 50 \\
\hline
\end{tabular}

\section{RESULTADOS Y DISCUSIÓN}

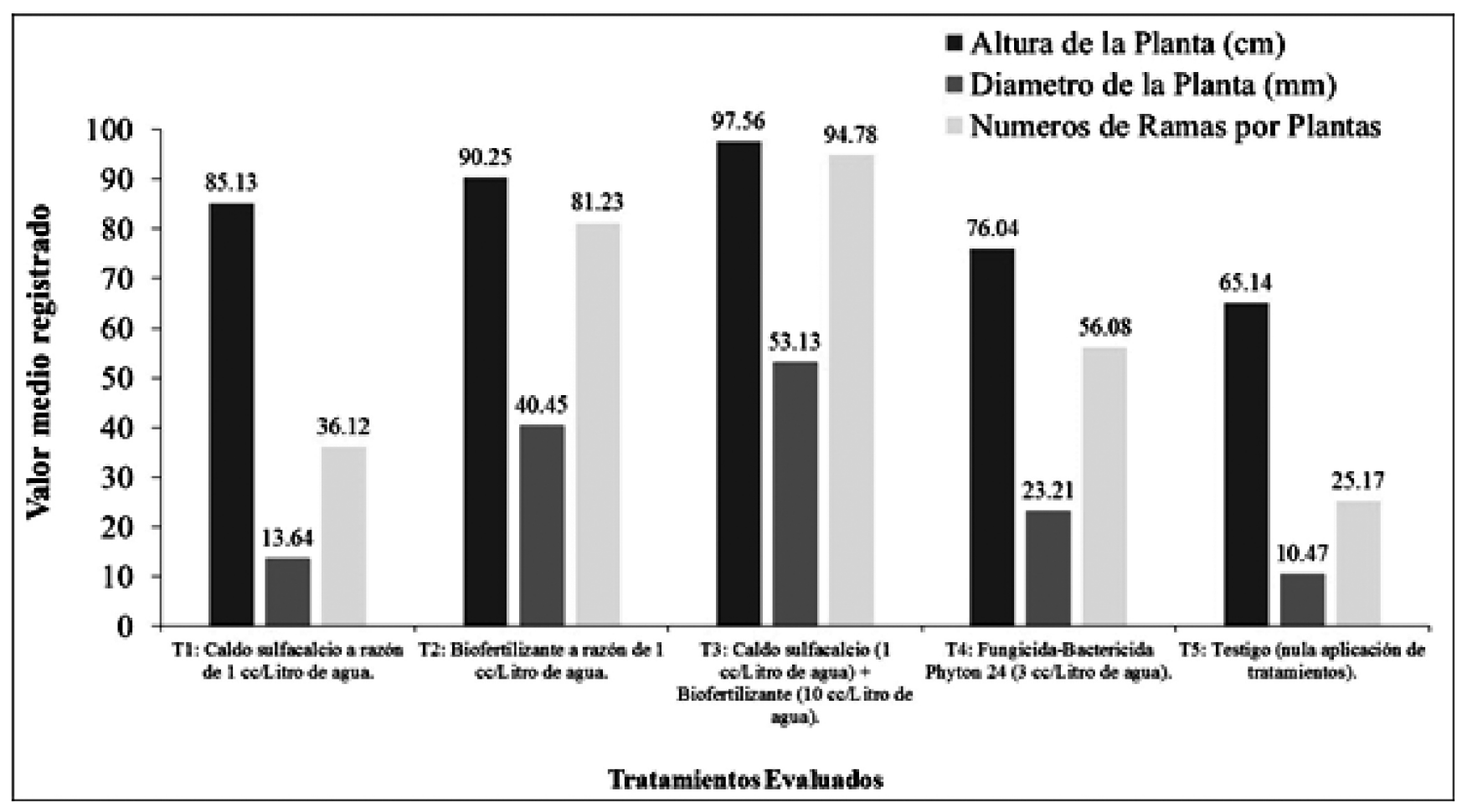

Figura 1. Efecto de los tratamientos evaluados en las variables fenológicas de las plantas de pino caribe (Pinus caribaea).

En cuanto a la altura $(\mathrm{cm})$, el análisis de varianza (ANOVA) demostró que el tratamiento 4 (T4) obtuvo $85,13 \mathrm{~cm}$ (P-valor $<0.001)$, siendo este uno de los tratamientos menos efectivos para el desarrollo óptimo de la especie en estudio. En cambio, en el segundo tratamiento, de manera general las plantas alcanzaron una altura de $90,25 \mathrm{~cm}$, siendo más eficiente que el primer tratamiento en cuanto al crecimiento de Pino Caribe (Pinus caribaea) en viveros (P-valor: 0.026). Obteniendo como resultado $\mathrm{T} 2-\mathrm{T} 1=5,12 \%$ en com- paración con el primer tratamiento. Esto de acuerdo a los resultados obtenidos durante la investigación de especies de Pino Caribe.

En el tratamiento número 3, la altura de las plantas fue de $97.56 \mathrm{~cm}$ logrando uno de los mejores resultados (P-valor: 0.002), y en donde las plantas alcanzaron un crecimiento eficiente en comparación con el tratamiento número 1 (caldo sulfacalcio a razón de $1 \mathrm{cc} /$ litro de agua) y tratamiento número 2 (biofertilizante a razón de $1 \mathrm{cc} /$ Litro de agua). De igual manera, estos 
resultados de forma global fueron los más significativos en comparación con los tres tratamientos: T1, T2 y T3 (caldo sulfacalcio a razón de 1 cc/litro de agua + Biofertilizante $10 \mathrm{cc} /$ litro de agua).

En el cuarto tratamiento se aplicó fungicida-bactericida Phyton 24 (3 cc/Litro de agua) fue el que hizo que las plantas alcanzaran el siguiente menor crecimiento, obteniendo los resultados de $76,04 \mathrm{~cm}$ de altura de manera general, marcando diferencia estadística con el tratamiento más alto.

En cuanto al diámetro $(\mathrm{mm})$ de las plantas se obtuvo los siguientes resultados: $\mathrm{T} 1=$ Caldo sulfacalcio a razón de $1 \mathrm{cc} /$ Litro de agua 13,64 mm; T2= Biofertilizante a razón de $1 \mathrm{cc} /$ Litro de agua 40,45 mm, T3= Caldo sulfacalcio (1 cc/Litro de agua) + Biofertilizante $(10 \mathrm{cc} /$ Litro de agua) $53,13 \mathrm{~mm}, \mathrm{~T} 4=$ Fungicida - Bactericida Phyton 24 (3 cc/Litro de agua) 23,21 $\mathrm{mm}$, presentado resultados no significativos (P-valor: 0.736) al realizar el análisis de varianza (ANOVA). Los resultados óptimos fueron en el T3, con un promedio de 53,13 $\mathrm{mm}(33,13 \%$ superior $)$ de manera global, sobrepasando a todos los demás tratamientos, lo cual permite afirmar que el Biofertilizante fue una sustancia apropiada para el crecimiento alcanzado por las plantas estudiadas, sin embargo, no se identifica crecimiento mayor o efectos negativos por uso de las otras sustancias ensayadas.

De acuerdo al número de ramas por planta se obtuvo, de manera general, los siguientes resultados: Tratamiento 1: caldo sulfacalcio a razón de $1 \mathrm{cc} /$ litro de agua 36,12 ; tratamiento 2: biofertilizante a razón de $1 \mathrm{cc} /$ Litro de agua 81,23 número de ramas por plantas, Tratamiento 3: Caldo sulfacalcio (1 cc/Litro de agua) + Biofertilizante $10 \mathrm{cc} /$ Litro de agua) 94,78 y tratamiento 4: Fungicida -Bactericida Phyton 24 (3 cc/litro de agua) 56,08 número de ramas por planta. Se obtuvieron los mejores resultados en cuanto al desarrollo de las ramas de las plantas de pino caribe fue el tratamiento 3 en donde se aplicó una combinación de dosis de Caldo Sulfacalcio 1 cc/Litro de agua más Biofertilizantes $10 \mathrm{cc} /$ Litro de agua (P-valor $<0.001)$.

Por último, en el tratamiento 5, conocida como testigo o muestra nula, no se le denomina así porque no se aplicó ningún caldo mineral ni Biofertilizante; sin embargo, en esta muestra se pudo observar la afectación por patógenos en un rango de 25,17 en cuanto al crecimiento de las hijas por plantas. Esto se debió a que no se aplicó ni fertilización ni ningún tipo de tratamiento.

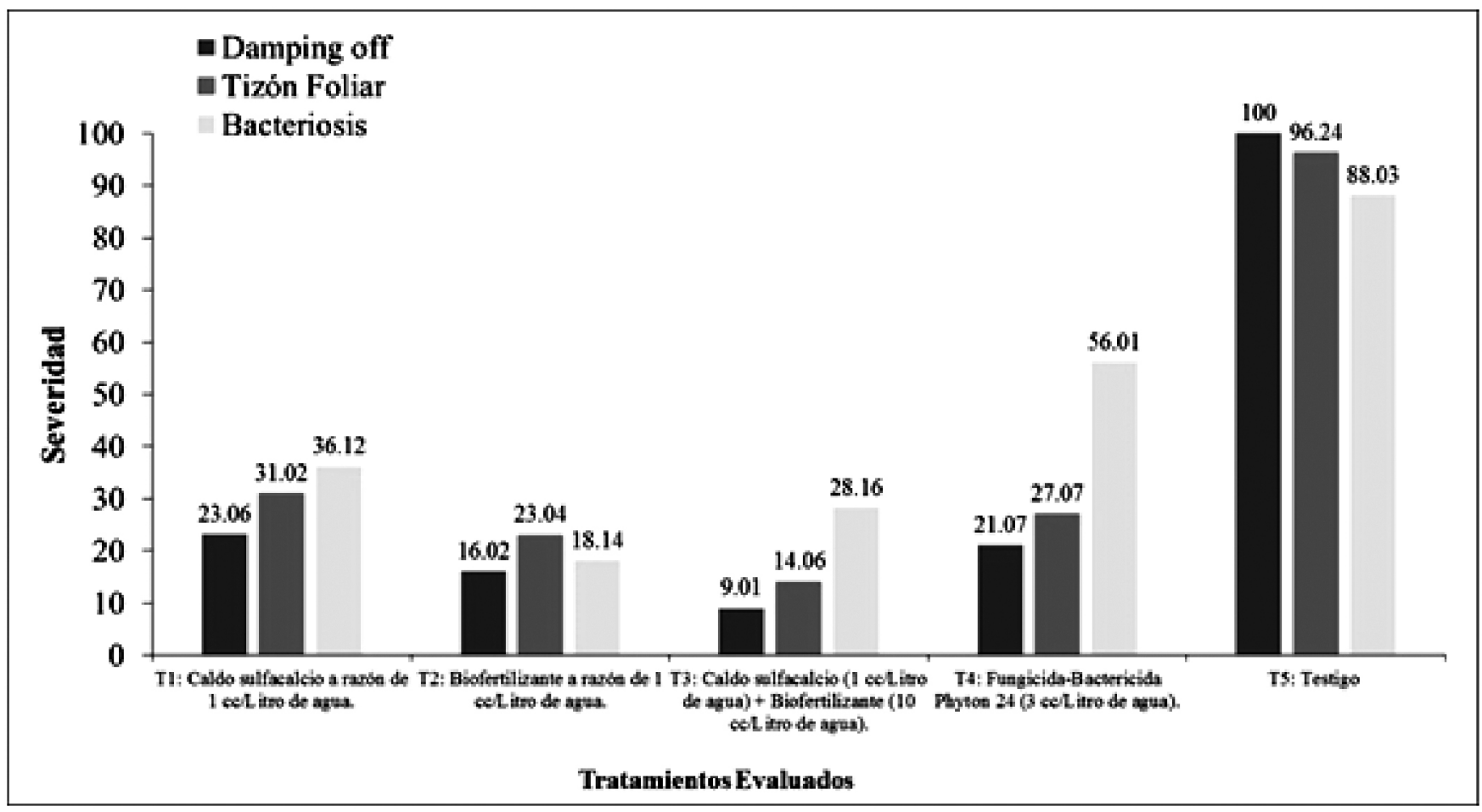

Figura 2. Análisis del Control de Patógenos por tratamiento en plántulas de Pino Caribe (Pinus caribaea). 
En la figura 2 se representa la incidencia de los patógenos que afectaron las plantas en esta investigación contrastado con la efectividad de aplicación de caldos minerales en Pino Caribe (Pinus caribaea) como mecanismo de control del Damping off. Durante los diferentes muestreos se pudo apreciar tres tipos de patógenos Mal del talluelo Tizón foliar, Bacteriosis que en su conjunto generan el conocido Damping off,. Los patógenos referidos mostraron sintomatología ochos días posteriores a la germinación de las plántulas. Con ello se da inicio a la aplicación de los tratamientos de control curativo.

el análisis de incidencia y poder currativo de los patógenos identificados y los tratamientos empleados indica que en el primer tratamiento de caldos sulfacalcio se obtuvo como resultado de $23,06 \%$ de presencia de Damping off en las primeras cincuenta plantas que correspondieron al tratamiento 1. Seguidamente en el segundo tratamiento se aplicó Biofertilizante se obtuvo $16,02 \%$ de plantas afectadas por Damping off, en la Tratamiento número 3 se aplicó caldo sulfacalcio más Biofertilizante coincidió la presencia Damping off que corresponde a 9,01\% de afectación. En el cuarto tratamiento se aplicó Fungicida-Bactericida Phyton 24 de manera general la afectación en la muestra número 4 fue de $21,07 \%$ de afectación por el patógeno Damping off. En el último muestreo no se aplicó ningún tratamiento; sin embargo, se encontró presencia de Damping off en 100\%. En gráfico número dos se encontró presencia del patógeno Tizón Foliar afectando en el primer tratamiento con $31,02 \%$ siendo en las primeras 50 plantas unos de los que se logró prevenir afectación, en el segundo tratamiento se identificó la presencia de Tizón Foliar en 23,04\% ocupando el segundo lugar se logró mitigar la afectación de las plantas de Pino Caribe (Pinus carib$a e a)$. En el tratamiento número 3 se aplicó Caldo sulfacalcio más Biofertilizante este tratamiento fue el que se apreciaron mejores resultados en cuanto a la prevención de la enfermedad llamada Tizón Foliar con $14,06 \%$ de afectación.

En el cuarto tratamiento se aplicó Fungicida - Bactericida Phyton 24 con una dosis (3 cc/Litro de agua) encontrándose una afectación de $27,07 \%$ por el patógeno Tizón Foliar ocupando un segundo lugar en cuanto el daño que provoco este esta enfermedad en las plantas de Pino Caribe (Pino caribaea), es de- cir, una vez identificado el patógeno se procedió a la aplicación de esta sustancia para poder controlar la propagación e infestación de las demás plantas por esta enfermedad. Por último, en la muestra 5 (testigo o muestra nula) solo se le dio mantenimiento control de maleza y riego permanente con agua al igual que los otros cuatro tratamientos, pero si se encontró la presencia de la enfermedad denominada Bacteriosis en un rango de $96,24 \%$.

En esta investigación realizada con Pino Caribe ( $P i$ nus caribaea) en condiciones de vivero, en la figura 2 se valoró la presencia, incidencia y severidad de la enfermedad mal del talluelo o mejor conocida como Bacteriosis en el muestreo 1 se aplicó caldo sulfacalcio a razón de $1 \mathrm{cc} \neg$ /Litro de agua, sin embargo, se encontró esta enfermedad con afectación del 36,12\% siendo esta muestra la más afectadas por el Bacteriosis. En el tratamiento 2 se identificó esta enfermedad con afectación del 18,14\%, luego se procedió a combatir la enfermedad con Biofertilizante a razón de $1 \mathrm{cc} /$ Litro de agua en esta muestra la afectación del Bacteriosis ocupó el segundo lugar; sin embargo, el uso de Biofertilizante permitió que no se siguiera propagando la enfermedad a las demás plantas.

En el tratamiento tres se aplicó caldo sulfacalcio $1 \mathrm{cc} /$ Litro de agua + Biofertilizante $10 \mathrm{cc} /$ litro de agua; Sin embargo, la afectación que se encontró fue de un $28,16 \%$ de siendo esta combinación de caldos minerales uno de los más efectivos para combatir este tipo de enfermedad pudiendo demostrar que para obtener plántulas de pino de calidad en viveros es importante combatir y control las enfermedades con caldos minerales. En el tratamiento 4 se aplicó Fungicida - Bactericida Phyton 24 (3 cc/litro de agua) no obstante se presenció la enfermedad (Bacteriosis) con una afectación de $56 \%$ de manera general en este muestreo lográndola combatir con esta sustancia y disminuyendo su impacto en cuanto a la propagación de la enfermedad.

En la muestra nula o testigo del gráfico número 2 se identificó la presencia de la enfermedad mal del talluelo (Bacteriosis), pero a esta, pero a esta no se le aplicó ningún tipo de tratamiento solo con su mantenimiento, riego y control de maleza, pero se presenció la enfermedad en $88,03 \%$ de afectación a las plantas de Pino Caribe (Pinus caribaea). 


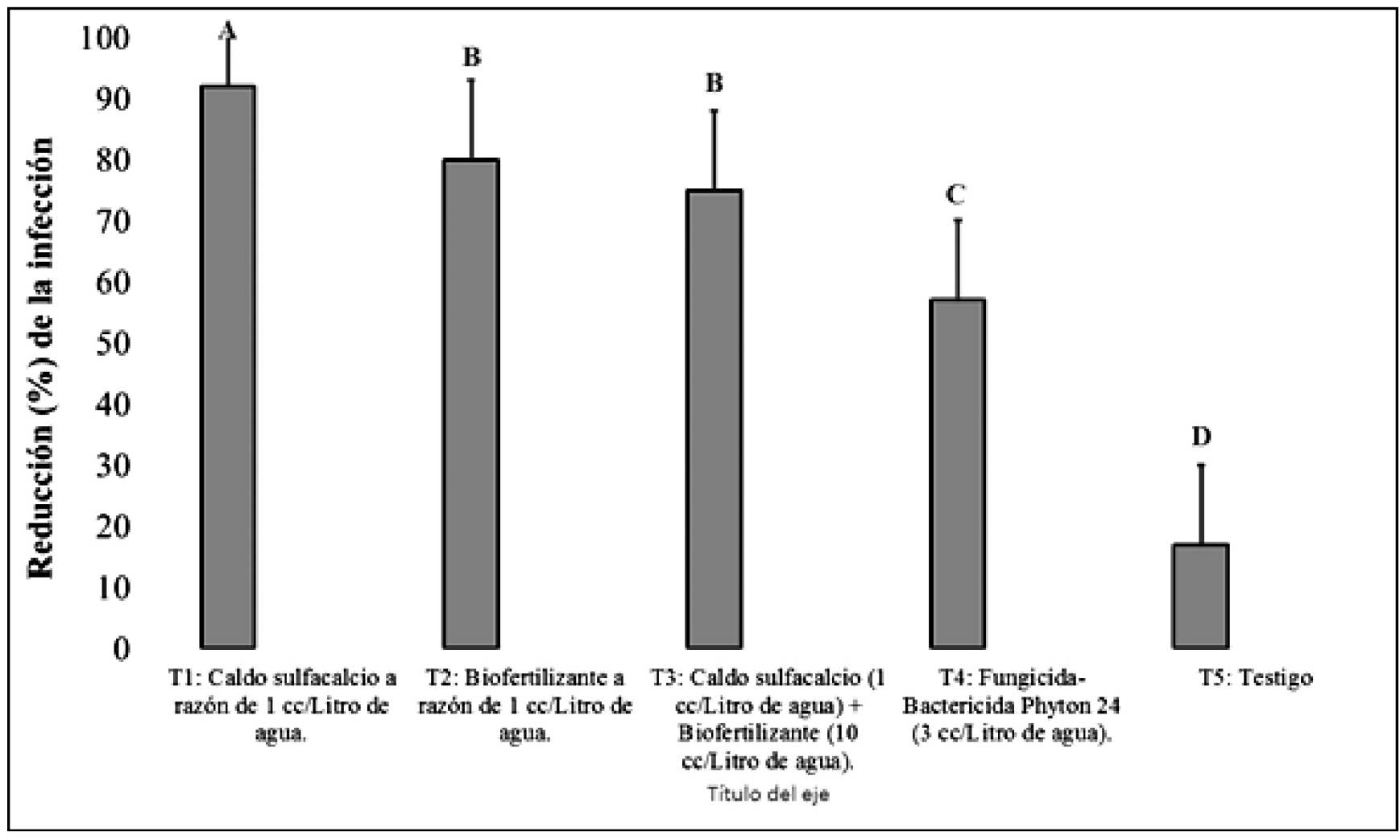

Figura 3. Control curativo por patógenos identificados y por tratamiento en plántulas de Pino Caribe (Pinus caribaea). Letras distintas (A-D) representan diferencias estadísticamente significativas al 95\% de confiabilidad.

En el segundo tratamiento se pudo demostrar que un $14 \%$ fue la afectación por el patógeno mal del ta1luelo. Se utilizó una escala de $100 \%$ para medir que la prevalencia de la enfermedad ante la prevención del patógeno con Biofertilizante como mecanismo de control del Damping off. En el tercer tratamiento se aplicó una combinación con diferentes dosis caldo sulfacalcio (1 cc/Litro de agua) + Biofertilizante (10 cc/Litro de agua) como mecanismo de control a la presencia de los patógenos: Tizón Foliar, Bacteriosis y Mal del Talluelo (complejo Damping off) en los diferentes muestreos realizados durante la investigación se valoró el efecto que tuvo la aplicación Caldo Sulfacalcio y Biofertilizante encontrándose un $100 \%$ de presencia de lo patógeno; sin embargo, la utilización de la combinación de estos caldos se pudo prevenir la propagación de los patógenos a las demás plantas teniendo como resultado para prevenir que un vivero sea afectado por estas enfermedades y de esa forma poder obtener plantas de calidad para plantarse en el campo.
Los resultados muestran que la fertilización aumenta la sobrevivencia en plántulas de Pinus caribaea en presencia de Damping off,. El N (nitrógeno) parece ser el principal nutriente responsable del incremento de la fuerza, mientras que el $\mathrm{P}$ (fósforo) y el K (potasio) tienen un efecto aditivo cuando son aplicados junto con el $\mathrm{N}$ en la formulación del Biofertilizante. Estudios anteriores avalan que el exceso de $\mathrm{N}$ puede aumentar la producción de respuestas defensivas de la planta respecto a algunos patógenos. Las adiciones de fertilizantes orgánicos con $\mathrm{N}$ y $\mathrm{P}$ en plantaciones de Pinus elliotti infectadas con F. circinatum decrementan la mortalidad y merman la severidad en los árboles (Ridley et al., 2000; Baralt et al., 2012). Asimismo, Baralt et al., (2012), observaron que plántulas de Pinus virginiana fertilizadas presentan mayor resistencia a los patógenos en la fase de viveros. Sin embargo, Hahn (1984) reportó que la elevada fertilización con $\mathrm{N}$ incrementa la mortalidad de plantas atacadas por el hongo Damping off. En cambio, autores 
como Sánchez y Murillo (2004) proponen el empleo de fertilizantes como una de las posibles herramientas para disminuir otros hongos patógenos, como Damping off.
La quinta muestra, el testigo muestra que fue la más afectadas, esto se debe a que no se aplicó ningún tipo de caldo mineral ni Biofertilizante se demuestra a través de los monitoreos perjudico un $100 \%$ de afectación por los patógenos Damping off en las plantas de Pino Caribe.

Tabla 2. Comportamiento de la Severidad de Damping off, para cada tratamiento evaluado. Grados libertad (gl), F calculada $(\mathrm{Fc})$ y F tabular (Ft), alfa $\alpha=0.005 . *$ Indica Diferencia Estadística Significativa a un $95 \%$ de confiabilidad.

\begin{tabular}{|c|c|c|c|c|c|c|}
\hline & Tratamientos Evaluados & Suma de cuadrados & $\mathrm{gl}$ & Media cuadrática & $\mathrm{Fc}$ & $\mathrm{Ft}$ \\
\hline \multirow{3}{*}{$\mathrm{T} 1$} & Inter-grupos & 0 & 4 & 0 & $12.57 *$ & 0 \\
\hline & Intra-grupos & 5211429 & 21260 & 0.245 & & \\
\hline & Total & 5211429 & 21279 & & & \\
\hline \multirow{3}{*}{$\mathrm{T} 2$} & Inter-grupos & 0 & 19 & 0 & $11.94 *$ & 0 \\
\hline & Intra-grupos & 707560 & 21278 & 33253 & & \\
\hline & Total & 707560 & 21279 & & & \\
\hline \multirow{3}{*}{$\mathrm{T} 3$} & Inter-grupos & 47309 & 4 & 2.49 & $10.88 *$ & 0 \\
\hline & Intra-grupos & 3154281 & 13781 & 0.229 & & \\
\hline & Total & 3201.59 & 13800 & & & \\
\hline \multirow{3}{*}{$\mathrm{T} 4$} & Inter-grupos & 0 & 4 & 0 & $14.35 *$ & 0 \\
\hline & Intra-grupos & 5320 & 21260 & 0.25 & & \\
\hline & Total & 5320 & 21279 & & & \\
\hline \multirow{3}{*}{ T5 } & Inter-grupos & 523471 & 4 & 523471 & 0 & 1 \\
\hline & Intra-grupos & 503305 & 13799 & 36474 & & \\
\hline & Total & 503828.5 & 13800 & & & \\
\hline
\end{tabular}

Los datos expuestos en la tabla 2 se muestran que la que el primer tratamiento en la severidad y virulencia del patógeno Damping off, en una escala de 0.0 a 1.5 la afectación de este patógeno fue un $100 \%$ envista que alcanzo los límites que eran 1.5 , es decir, en la investigación estuvo presente el patógeno en estudio; sin embargo, la utilización de caldo mineral caldo sulfacalcio como mecanismo de control para combatir este patógeno que afecta principalmente a las plantas en etapa de viveros. En el segundo tratamiento de la tabla Numero 2 se aplicó Biofertilizante a razón de $1 \mathrm{cc} /$ litro de agua a las plantas de pino en vivero como mecanismo de control al patógeno del Damping off; sin embargo, la afectación disminuyo en comparación al primer tratamiento porque su afectación fue de un $98 \%$ siendo el Biofertilizante una sustancia para con- trolar los patógenos y dar un óptimo desarrollo de las plantas.

En el tercer tratamiento la tabla 2 se pudo demostrar que la combinación del caldo Sulfacalcio + Biofertilizante fue una sustancia indispensable para combatir la severidad y virulencia del patógeno esto se debe a que disminuyo la propagación del patógeno Damping off, uno de los resultados más eficiente en cuanto a reducir la afectación y propagación de la enfermedad a las plantas que se encontraban en un estado sanas y actas para poder ser llevadas acampo y poder producir plantas de calidad en un futuro. El fungicida bactericida utilizado en la investigación tuvo un efecto considerado bueno para combatir la severidad y virulencia del patógeno mal del talluelo en vista que es 
una sustancia para controlar la afectación de hongos y agentes patógenos que afectan a las plantas en etapa de viveros esto se debe que las enfermedades atacan a las plantas en etapa de vivero porque están más susceptibles, es decir, tienen menor capacidad para resistir enfermedades relacionadas a virus fue por ello la experimentación de esta sustancia para combatir los hongos como el Tizón Foliar y Bacteriosis en especies de Pino Caribe.

En la muestra número cinco fue una muestra experimental sin ningún tipo de tratamiento para controlar las enfermedades en estudio, severidad y virulencia de los patógenos, siendo esta muestra testigo que se pudo apreciar durante la investigación la presencia del mal del talluelo provocando muertes de plántulas esto se debió por qué no se hizo uso de caldos minerales para combatir la propagación de las enfermedades antes descritas. En la tabla 2 se demuestra la capacidad de propagación y virulencia del patógeno que afecto a las plantas de pino en vivero, de acuerdo a los diferentes muestreos realizados durante el ciclo de la investigación se observó la afectación del patógeno Damping off, en los cinco tratamientos en donde se observó que la afectación sobre paso los límites planteados; sin embargo, la acción de los caldos minerales $\mathrm{y}$ el Biofertilizante tuvo un efecto satisfactorio en vista que la mitigación ante daños provocados por los patógenos Damping off fue de un 95\%; para producir plantas de calidad en vivero se tiene que tomar en cuenta el tipo de sustancia o caldo mineral se debe implementar como mecanismo de control curativo y preventivo ante enfermedades relacionadas con reducir plántulas degradadas por agentes patógenos que por lo general afectan a las plántulas en etapa de vegetativo.
Se apunta a dos hipótesis para explicar el incremento de susceptibilidad de plántulas cuando no se fertiliza: (i) para el éxito en la colonización de una planta por un patógeno requiere de la utilización de los nutrientes presentes en los tejidos. Por ello, la carencia de nutrientes en los tejidos de las plantas generaría un medio más débil y susceptible para la entrada y el crecimiento del patógeno (Crous, 2002), y (ii) una disminución en la disponibilidad de nutrientes puede alterar el reparto de energía en las plantas, en detrimento de los sistemas defensivos. Ganley (2011) plantea que el balance crecimiento-diferenciación $(\mathrm{GDBH})$, según el cual existe un equilibrio fisiológico entre el crecimiento y el metabolismo secundario, impuesto por el desarrollo limitado de las células en crecimiento. En este ensayo, la fertilización podría desplazar el balance hacia tasas de crecimiento relativas mayores, de modo que aumenta la calidad nutricional de la plántula en a favor del nivel de metabolitos secundarios que inhiben el desarrollo del patógeno, aumentando las defensas de la plántula. Esta afirmación contradice resultados obtenidos ante patógenos que afectan con mayor intensidad a árboles adultos con poco vigor (ej. Heterobasidion annosum), en los que la fertilización reduce la resistencia a las enfermedades.

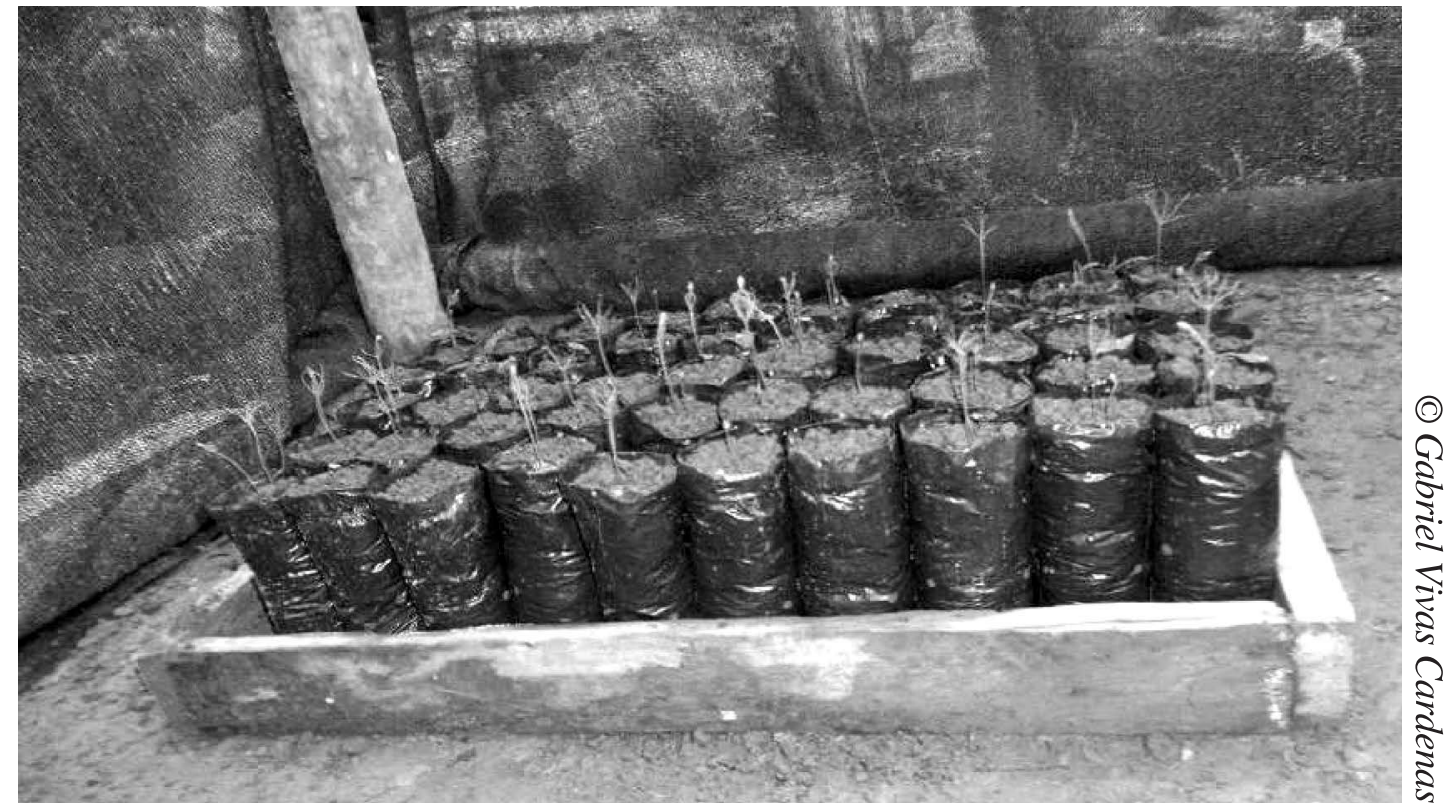

Almácigos de las plántulas objetos de la investigación. Foto: Gabriel Vivas Cárdenas. 


\section{CONCLUSIÓN}

La aplicación Caldo Sulfacalcio $\left(T_{1}\right)$ y Biofertilizante $\left(T_{2}\right)$, y las combinaciones de estos $\left(T_{3}\right)$ caldos se pudieron prevenir la propagación de los patógenos causantes del mal del talluelo o Damping off post germinación, Tizón Foliar y Bacteriosis a las demás plantas teniendo como resultado significativo (P-valor $>0.05$ ) evitando que el resto del vivero fuera afectado, además se obtuvieron plantas de mayor calidad para sembrarse en el campo. Estos resultados permiten aceptar la hipótesis alternativa ya que se demuestra diferencia significativa entre los tratamientos a un $95 \%$ de confiabilidad.

Los caldos minerales y biofertilizantes y sus mezclas estudiados en esta investigación reducen la afectación de Damping off en Pino Caribe (Pinus caribaea), en condiciones post-emergerte de plántulas. Presentando una mayor efectividad la aplicación de la mezcla de calcio sulfacalcio y biofertilizantes $\left(\mathrm{T}_{3}\right)$.

\section{REFERENCIAS}

Alcaldía Municipal de San Fernando. 2007 www.cgr.gob.ni/cgr/index.php?option=com_docman\&task en Credencial de referencia MCS-CGR-190-10-2007 de fecha 4 de octubre de conformidad con Principios de Contabilidad Gubernamental de Nicaragua, Alcaldía Municipal de San Fernando y de la Contraloría General de la República. Disponible en Línea: https://www.google.com.ni/search?q=Alcaldia+de+san+fernando+Nicaragua $+2007 \&$ ei $=$ AXZsVc2AA9HIsATrzYLAD

Altieri, M. A.: Agroecología. Bases Científicas para una Agricultura Sustentable. La Habana: Consorcio Latino Americano sobre Agroecología y Desarrollo, 1997. http://www.ecured.cu/index.php/Biofertilizantes.

Baralt, A. E., Fernández, R., Sosa, D., Iztúriz, M. A., Parra, D., \& Pérez, S. (2012). Identificación preliminar de hongos endófitos cultivables presentes en hojas y frutos de cacao. 2. In Primer congreso Venezolano de Ciencias, Tecnología, e Innovación. Retrieved from http://www.fundacite-merida.gob.ve/images/doc/documentos/ aprobados.pdf

Birchler, T., R.W. Rose. A. Apoyo y M. Pardos. 1998. La Planta ideal: revisión de conceptos, parámetros definitorios e implementación práctica. Investigación agraria. Sistema y Recurso Forestal. Oregón State University. Vol. 7 (1): 109-122.

Crous, P. W. 2002. Taxonomy and pathology of Cylindrocladium (Calonectria) and Allied genera. The American Phytopathological Society Press, Minnesota. 278 p.

Ganley, R. J., Watt, M. S., Kriticos, D. J., Hopkins, A. J. M., \& Manning, L. K. (2011). Increased risk of pitch canker to Australasia under climate change. Australasian Plant Pathology. http://doi.org/10.1007/s13313-011$0033-2$

Gordon, T. R., Swett, C. L., \& Wingfield, M. J. (2015). Management of Fusarium diseases affecting conifers. Crop Protection. http://doi.org/10.1016/j.cropro.2015.02.018

Hahn, P. F. 1984. Plug Seedling production. In: Forest Nursery Manual. Production of Barefoot Seedling. M. L. Duryea and.T. D. Landis (Eds.). MartinusNijhoff/Dr. W. Jun k Publishers. Oregon Sta. University, Corvallis. Oregon. pp: 161-181.

IBM ${ }^{\circledR}$ Statistical SPSS. 2016. IBM® SPSS 24.0. Statistical Package for the Social Sciences. Available at: http://www.spss.com/. 
Instituto Nacional Forestal (INAFOR). 2008. Informe del Inventario Nacional Forestal (Versión Inafor.www. inafor.gob.ni/inventario/Pdfs/Informe\%20Final\%20.pdf Resultados del Inventario Nacional Forestal: Nicaragua 2007-2008/INAFOR. $-{ }^{\mathrm{a}}{ }^{\mathrm{a}}$ ed.... Wing León Lau Williams, Director INF • Juan Carlos Moncada, Informática. http://www.inafor.gob.ni/inventario/Pdfs/Informe\%20Final\%20.

Instituto Nacional Forestal (INAFOR- POSAF) - Nicaragua. 2006. Guía Técnica II; Establecimiento y Manejo de Regeneración Natural de Pinos y/o Plantaciones (Enriquecimiento). (En línea). Consultado 20 de marzo del 2014. Disponible en: http://www.inafor.gob.ni: 8080/documentos_tecnicos/pdf/Guias\%20Metodol\%C3\%B3 gicas\%20para\%20el\%20Manejo\%20Forestal/Guia\%20Tecnica\%20de\%20apoyo\%20al\%20pRoductor\%20 Forestal\%20Para\%20Establecimi.pdf

Moya A. 1975. Manual de Vivero. Dirección de Recursos Naturales Renovables. DIRENARE. MAG.

Patton, RF. 2003. En: Hansen, EM. Lewis, KJ. Plagas y enfermedades de las confieras. 2da.Ed. España, Ediciones Mundi-Prensa. 56, 57, 58 p.

Programa de las Naciones Unidas para el Desarrollo (PNUD). 2006. Informe sobre Desarrollo Humano. Publicado para él. Programa de las. Naciones Unidas para el Desarrollo. Más allá de la escasez: Poder, pobreza y la crisis mundial.

R-Development-Core-Team. 2013. R Core Team. R: A language and environment for statistical computing.

Ridley, G. S., \& Dick, M. a. (2000). Pine pitch canker disease: the name of the causal fungus and its distribution. Australasian Plant Pathology, 29(4), 263-266.

Sánchez, S., y O. Murillo. 2004. Desarrollo de un Método para Controlar la calidad de la Producción de Plántulas en viveros forestales: estudio de caso con ciprés (cupressuslusitancia). Agronomía Costa Rícense 28 (2): 95-106. 